\title{
MINERAÇÃO E RELEVO ANTROPOGÊNICO, O EXEMPLO DA EXTRAÇÃO DE ESTEATITO EM SANTA RITA, OURO PRETO, MINAS GERAIS
}

\author{
Henrique Amorim Machado \\ Universidade do Estado de Minas Gerais (UEMG) \\ Unidade Ituiutaba, Agronomia, Ituiutaba, MG, Brasil \\ henrique.mahchado@uemg.br \\ Renata Jordan Henriques \\ Universidade Federal de Minas Gerais (UFMG) \\ Instituto de Geociências, Pós-Graduação em Geografia, Belo Horizonte, MG, Brasil \\ renatajhques@gmail.com \\ Ronaldo Ferreira de Souza \\ Instituto Federal de Minas Gerais (UFMG) \\ Campus Ouro Preto, Graduação em Geografia, Ouro Preto, MG, Brasil \\ ronaldoadmufop@gmail.com
}

\begin{abstract}
RESUMO
As formas de relevo são modeladas por diversos fatores ambientais, sendo o agente humano um importante elemento que também modela e altera a paisagem. A mineração é uma das principais atividades antrópicas responsáveis por afetar a fisiologia do relevo e suas formas. Este trabalho objetivou investigar as influências humanas na gênese de feições de relevo a partir da atividade de uma cava de extração de esteatito situada no distrito de Santa Rita, pertencente ao município de Ouro Preto, Minas Gerais. Para isso foi realizado levantamento aerofotogramétrico com uso de sistemas de aeronaves remotamente pilotadas - RPAS, sendo geradas as bases de altimetria, curvas de nível equidistantes de $1 \mathrm{~m}$, ortofotomosaico e cálculo de volume de materiais. Como resultado foi possível identificar formas de relevo fortemente relacionadas às atividades antrópicas, capazes de alterar o regime de fluxos sedimentares e hidrológicos, bem como a amplitude altimétrica da área. $O$ trabalho evidenciou como o agente humano é um importante fator a ser considerado, sobretudo, na fisiologia da paisagem em escalas cada vez mais localizadas, que somadas podem reverberar regionalmente. Para tanto, o uso de bases cartográficas em escala adequada é uma das principais ferramentas para os avanços nas discussões acerca de formas e processos atuantes em relevos antropogênicos.
\end{abstract}

Palavras-chave: Relevo Antropogênico. Esteatito. Geomorfologia. Drone

\section{MINING AND ANTHROPOGENIC RELIEF, THE EXAMPLE OF STEATITE EXTRACTION IN SANTA RITA, OURO PRETO, MINAS GERAIS}

\begin{abstract}
The landforms are shaped by several environmental factors, the human agent being an important element that also shapes and changes the landscape. Mining is one of the main human activities responsible for affecting the physiology of the relief and its shapes. This work aimed to investigate the human influences in the genesis of relief features from the activity of a steatite extraction pit located in the district of Santa Rita, belonging to the municipality of Ouro Preto, Minas Gerais. For this, an aerophotogrammetric survey was carried out using vant, generating altimetry bases, $1 \mathrm{~m}$ equidistant contour lines, orthophotomosaic and calculation of material volume. As a result, it was possible to identify landforms strongly related to anthropic activities, capable of altering the regime of sedimentary and hydrological flows, as well as the altimetric amplitude of the area. The work showed how the human agent is an important factor to be considered, above all, in the physiology of the landscape in increasingly localized scales, which together can reverberate regionally. For this, the use of bases on an adequate scale is one of the main tools for advances in discussions about anthropogenic reliefs, since their scale demands the perception of processes that operate.
\end{abstract}

Keywords: Anthropogenic relief. Steatite. Geomorphology. Drone. 


\section{INTRODUÇÃO}

As formas do relevo resultam da interação entre forças endógenas e exógenas que, condicionadas pela longa temporalidade geológica dos processos, instigam o homem desde o desenvolvimento de sua racionalidade (SUMMERFIELD, 1991; CHRISTOFOLETTI, 1999; BARROS e VALADÃO, 2018). À medida que o homem aumenta suas interferências sobre os processos físico-químicos naturais, a gênese do relevo incorpora o fator exógeno antrópico para a modelagem da superfície sob regência de uma escala espaço-temporal que se aproxima mais da história humana em detrimento da perspectiva geológica (GOUDIE, 1993; HOOKE, 2000; FUJIMOTO, 2005; RODRIGUES, 2005; FELIPPE, et al.,2014; PELOGGIA, 2019).

A mineração é uma atividade com grande potencial de transformação do relevo, passível de modificar a fisiografia de extensas regiões (HANCOCK, et al., 2008; ANDRADE, 2012; WÓJCIK, 2013; BLACHOWSKI e MILCZAREK, 2014). Os incrementos tecnológicos trazidos pela revolução industrial e suas novas tecnologias empregadas à mineração, principalmente durante o século $\mathrm{XX}$ e $\mathrm{XXI}$, resultaram na intensificação das ações e compressão do tempo necessário para as transformações na paisagem (RODRIGUES, 2005; PRICE, et al, 2011).

Destaca-se que a produção científica voltada ao reconhecimento do homem enquanto agente modelador do relevo no Brasil é relativamente recente, cujas discussões são dadas, sobretudo, a partir da década de 1970 (BROWN, 1971; OLIVEIRA, et al., 2005). Minas Gerais possui forte tradição mineradora desde os primórdios do Brasil Colonial, e pouco se produziu até os dias atuais sobre a dimensão e os impactos decorrentes das interferências humanas na morfologia e fisiologia da paisagem.

A ausência de dados cartográficos em escalas que permitam a identificação e análise das modificações antropogênicas no relevo brasileiro é um dos maiores empecilhos para a produção científica neste tema. $O$ aumento na disponibilidade de satélites imageadores, com sensores de alta resolução espacial, assim como a popularização das novas tecnologias de imageamento a partir de sistemas de aeronaves remotamente pilotadas - RPAS (Remotely Piloted Aircraft System) se tornam, neste cenário, importantes ferramentas para suprir a carência de dados de bases e fomentar novas discussões (LANE e CHANDLER, 2003; LUZ; ANTUNES e RATTON, 2017)

Nesse contexto, o trabalho objetiva diagnosticar e apresentar as interferências humanas enquanto agente transformador das formas e processos do relevo, a partir do exemplo de uma mineradora de extração de esteatito no distrito de Santa Rita, Ouro Preto, Minas Gerais.

\section{METODOLOGIA}

\section{Área de estudo}

Ouro Preto é um município com extensão total de $1.245 \mathrm{~km}^{2}$ situado na porção centro-sul do estado de Minas Gerais, em uma região denominada Quadrilátero Ferrífero (QF). Regionalmente o QF é caracterizado por rochas do Arqueano, como os complexos granito-gnáissicos do embasamento cristalino, assim como as rochas do Proterozoico pertencentes aos Supergrupos Rio das Velhas e Minas (DORR, 1969; ALKMIN e MARSHAK, 1998). O distrito de Santa Rita se localiza a $30 \mathrm{~km}$ a sudoeste da sede do município de Ouro Preto, e tem como destaque econômico a exploração da "pedra-sabão" (esteatito) e do mineral talco. A área da cava está estabelecida na coordenadas 7727600m e $645400 \mathrm{~m}$, cujo principal acesso é dado pela rodovia MG-129, que conecta os municípios de Ouro Preto e Ouro Branco (Figura 1).

Em termos geológicos, a área da cava está situada no domínio do complexo Santo Antônio do Pirapetinga, de idade Meso-Neoarqueana. Esse complexo é caracterizado pela ocorrência de talco-cloritaxisto, serpentinito, metabasito, e ortognaisses tonalítico-trondhjemítico e granítico, com estrutura bandada e agmatítica (BALTAZAR, 2005). Para a cava investigada neste trabalho há a ocorrência majoritária do serpentinito e, secundariamente, de esteatito com concentrações variadas do mineral talco.

O relevo do município de Ouro Preto e seus distritos é caracterizado por serras de elevada altimetria e por formas de relevo condicionadas principalmente pela litoestrutura (SALGADO, 2006). A paisagem estudada possui uma miscelânea de morros dissecados de até $1300 \mathrm{~m}$ de altitude, com vertentes alongadas e

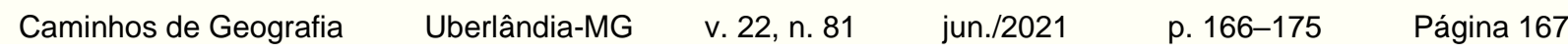


retilíneas, drenadas por uma densa rede fluvial. Mediante a variabilidade entre rochas tenras e duras, as formas do relevo apresentam fortes contrastes altimétricos, cujas áreas mais elevadas e serranas se desenvolvem principalmente a partir das rochas quartizíticas do Grupo Itacolomi. Entremeado às formas naturais também existem pilhas de rejeitos resultantes das atividades minerárias e de pequenas indústrias que influenciam a morfologia do relevo, em escala relativamente mais localizada.

\section{Etapas Metodológicas}

As etapas do estudo consistiram em trabalhos de campos realizados durante o período de junho a julho de 2019, para levantamento das principais áreas de mineração em Ouro Preto e região. Foi escolhida uma cava próxima ao distrito de Santa Rita, em razão da área apresentar formas de relevo relativamente nítidas acerca da escavação (extração do esteatito) e respectivos descartes adjacentes por meio de pilhas de rejeito. Em razão da fisiografia e organização espacial da cava, portanto, torna-se possível avançar sobre as discussões acerca do relevo antropogênico e as influências do homem sobre a fisiologia da paisagem. Para tanto, também foi realizada visita à sede administrativa da cava e sua unidade de beneficiamento, para se compreender a cadeia produtiva da atividade, visto que a comercialização imprime diferentes ritmos e sazonalidades dos impactos humanos.

Devido à necessidade do uso de base de dados cartográficos de maior resolução espacial para se trabalhar com feições e processos relativamente pontuais na paisagem, foi realizado levantamento aerofotogramétrico com uso de RPAS. Para isso foi utilizado o vant Phanton 4 advanced, da marca Dji, com a câmera acoplada modelo FC6310 de 20 megapixels de resolução e distância focal de $8.8 \mathrm{~mm}$. Para a confecção dos produtos cartográficos foi realizada a varredura de uma área de $0,292 \mathrm{~km}^{2}$ por meio do aplicativo Drone Deploy. Foram obtidas 177 imagens, de sobreposição frontal e lateral de $77 \%$, em uma altura de voo de cerca de $137 \mathrm{~m}$ de altitude, velocidade constante de $15 \mathrm{~m} / \mathrm{s}$ e resolução de pixels de $3,46 \mathrm{~cm}$.

Figura 1 - Localização da área de estudo e levantamento aéreo, produto ortofotomosaico.
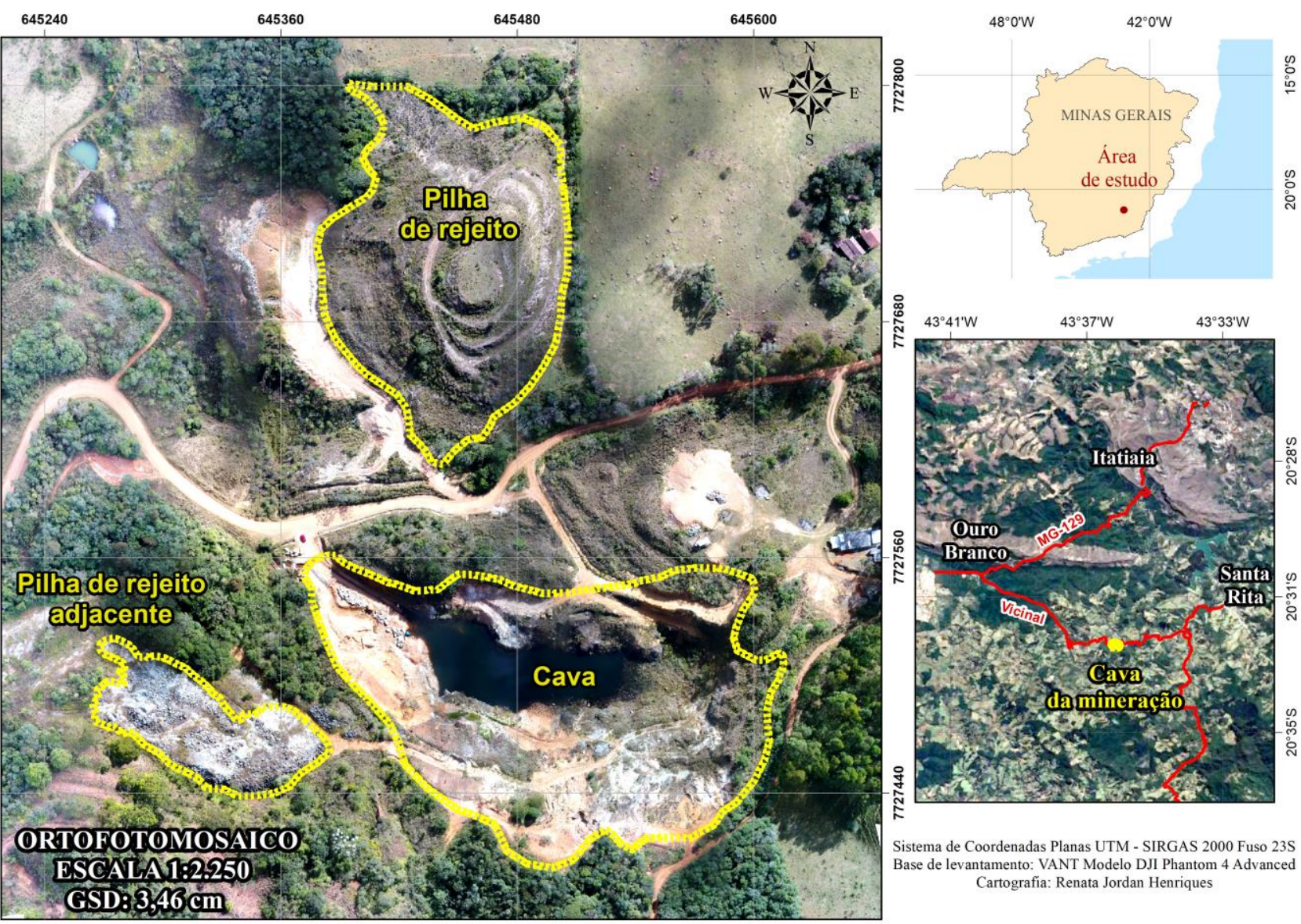

Caminhos de Geografia

Uberlândia-MG

v. 22, n. 81

jun./2021

p. $166-175$

Página 168 
As imagens foram tratadas no software Agisoft Metashape $1.5 .0^{\mathrm{R}}$, sendo gerado o modelo digital de elevação (MDE) em resolução de $13,8 \mathrm{~cm}$ a partir da nuvem de pontos em densidade de 52,3 pontos $/ \mathrm{m} 2$. Também foi gerado o ortofotomosaico a partir da união das 177 imagens levantadas. $O$ erro total estimado foi de $5,82 \mathrm{~m}$, sendo $X 0,87 \mathrm{~m}, Y 5,66 \mathrm{~m}, Z$ de $0,97 \mathrm{~m}$ e $X Y$ de $5,72 \mathrm{~m}$. Não foram utilizados pontos de controle a partir de dados GNSS por GPS geodésico em razão dos objetivos de o trabalho não exigirem a garantia da precisão centimétrica para esses dados. Foi realizado o cálculo estimado do volume da área da cava, bem como da principal pilha de rejeito. Os cálculos são realizados a partir da lâmina d'água no fundo da cava, o que pode subestimar os volumes extraídos, todavia, há confiabilidade nos valores em vista que a maior parte dos materiais são extraídos antes de se atingir o lençol freático.

Os dados foram projetados no sistema de coordenadas planas UTM SIRGAS 2000, fuso 23S. A partir dos produtos cartográficos, também foi realizado o cálculo volumétrico, ainda no ambiente do Agisoft Metashape 1.5.0 $0^{\mathrm{R}}$, bem como a extração de curvas de nível equidistantes de $1 \mathrm{~m}$. No software ArcGIS $10.3^{\mathrm{R}}$, por sua vez, foram elaborados os mapas dos produtos gerados.

\section{RESULTADOS}

\section{Formas de relevo e interferências hidrológicas antrópicas}

O relevo da área de estudo apresenta relativamente poucas variações altimétricas. No setor noroeste encontra -se a menor cota, de $1.040 \mathrm{~m}$, ao passo que a sudoeste o ponto mais, com $1.130 \mathrm{~m}$. Em termos hidrológicos e morfológicos, o setor sul da área de estudo referente à cava, às estradas vicinais e a presença de pilhas de rejeito é a principal área cujos processos antropogênicos mais agressivamente imprimiram modificações na paisagem e sua fisiologia (Figura 2).

A cava possui orientação sudeste-noroeste. A face sul da cava é a mais explorada, principalmente pelo aproveitamento do talco, sendo criados cortes escalonados de talude por meio de escavadeiras, conferindo declividades próximas de $90^{\circ}$ associadas a rampas planas de talude. Essa é uma das áreas de maior potencial erosivo, visto a pouca cobertura vegetal presente nesses taludes associada à exploração atual minerária (Figura 2). A face norte da cava evidencia um corte acentuado na rocha com pouco material ainda escavado e declives por volta de $70 \%$, o que expressa o menor interesse dos agentes mineradores ao longo da história da abertura da cava.

A face leste da cava, por sua vez, apresenta-se como uma área sem exploração vigente, com heranças de antigos cortes escalonados de talude. Esses taludes atualmente possuem diversos indicadores de forte processo erosivo, que resulta em assoreamento à jusante. Devido ao processo de desmonte desses taludes, progressivamente a declividade de suas rampas são atenuadas para cerca de $50 \%$ ou menos, sobretudo, mais próximo ao lago da cava (Figura 2C). Esse material coluvionar depositado, por sua vez, apresenta pedogênese ainda incipiente associada à colonização vegetal por espécies pioneiras predominantemente herbáceas e alguns arbustos.

No centro da cava está presente um corpo lêntico associado à exfiltração das águas do lençol freático em razão do processo histórico de escavação da cava. Esse corpo lêntico é responsável por periodicamente extravasar água para jusante pela face oeste-noroeste da cava e contribuir para o escoamento hidrológico, sobretudo, pluvial. Essa situação resultou na geração de uma nascente do tipo antropogênica, conforme os critérios de Felippe et al. (2014), uma vez que sua ocorrência deriva da atividade mineradora e não de processos essencialmente naturais.

A forma essencialmente côncava da área da cava também é responsável por gerar a canalização de fluxos, principalmente pluviais, juntamente ao carreamento sedimentar oriundo das faces desnudas dos taludes. Isso representa tanto o assoreamento físico do corpo hídrico, quanto a possível contaminação de suas águas externas e subsuperficiais por contaminantes provenientes da atividade mineradora, como 0 uso de maquinários. As águas do interior da cava, ao extravasarem pela face oeste, drenam principalmente pelas linhas de arruamentos, sendo essas também um importante fator antrópico de alteração da fisiologia do relevo. Isto é, mediante a abertura de vias, as águas do escoamento pluvial são direcionadas, sendo catalisado e ampliado o potencial erosivo e de vazão dessas águas. 
A menos de $200 \mathrm{~m}$ da cava encontra-se uma elevação de 30 metros, resultado da disposição de rejeitos da mineração da cava. O material sem potencial para aproveitamento econômico é composto majoritariamente por serpentinito em diferentes granulometrias, podendo variar de areia até blocos. A forma da pilha de rejeito, de formato ovalado e isolado, gerou vertentes de declives relativamente assimétricas, de declividades superiores a $38 \%$ em sua face leste-oeste, enquanto a face sudoestenordeste os declives não superam os $20 \%$. De modo geral, a morfologia da pilha de rejeito é relativamente concêntrica, com uma base de cerca de $6.500 \mathrm{~m}^{2}$ e um leve eixo de alongamento preferencial no eixo sulnorte (Figura 3).

Figura 2 - Organização espacial das formas de relevo e topografia na área de estudo, em B principais fluxos hidrológicos e sedimentares influenciados pela atividade humana, em $\mathrm{C}$ face leste da cava que apresenta antigos taludes abandonados e seus respectivos desmontes e assoreamento do lago da cava.

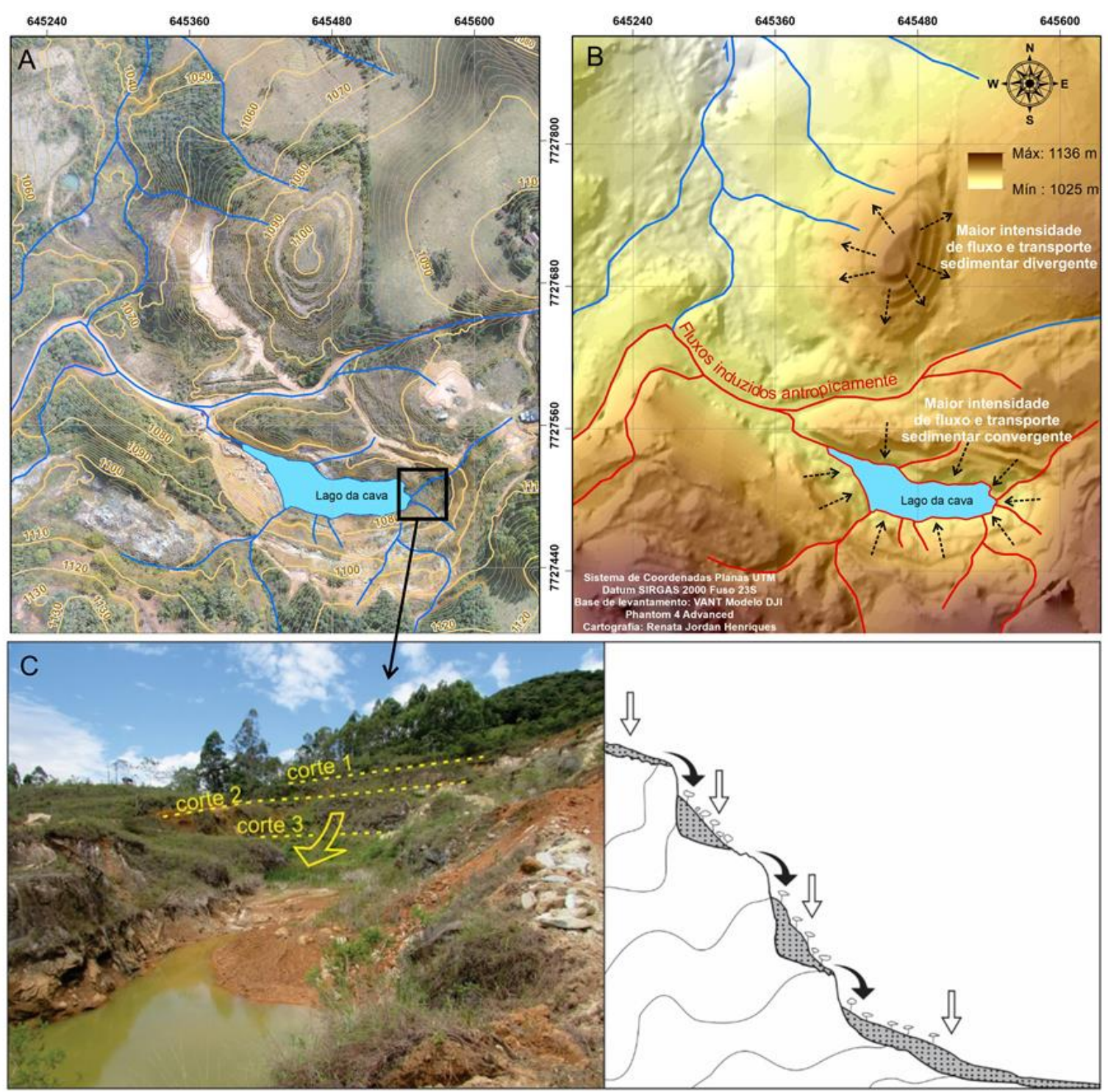

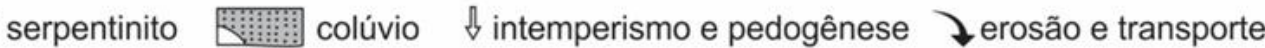

O alteamento desta feição encontra-se interrompida por questões legais, o que propiciou a colonização de vegetação e o desenvolvimento de processos pedogenéticos incipientes no material depositado. Todavia, em conversa com a administração da cava, o processo de licenciamento para reabertura da deposição de rejeitos está em andamento, o que fará com que a área volte a ser uma área de deposição, podendo resultar no aumento da área e altitude da pilha.

Caminhos de Geografia $\quad$ Uberlândia-MG $\quad$ v. 22, n. $81 \quad$ jun./2021 $\quad$ p. 166-175 Página 170 


\section{Alterações morfométricas}

As alterações na forma da paisagem após a implantação da cava levam ao entendimento de duas mudanças antagônicas, uma a partir da remoção de material, gerando feições côncavas na vertente, e outra a partir da deposição, que gera feições convexas.

O imageamento da área de estudo permitiu a estimação dos volumes retirados e adicionados na paisagem com precisão de detalhe. Foi possível mensurar a saída de $299.595 \mathrm{~m}^{3}$ de material da cava, referente à somatória de estéril, esteatito e serpentinito (Figura 4). Na pilha de rejeito, por sua vez, foi identificado $137.895 \mathrm{~m}^{3}$ de fragmentos compostos essencialmente por serpentinito. Por meio da diferença é possível estimar que cerca de $161.700 \mathrm{~m}^{3}$ de esteatito foram destinados às unidades beneficiadoras (Figura 4).

Figura 3 - Sistema de alteamento da pilha de rejeito e suas respectivas altitudes.

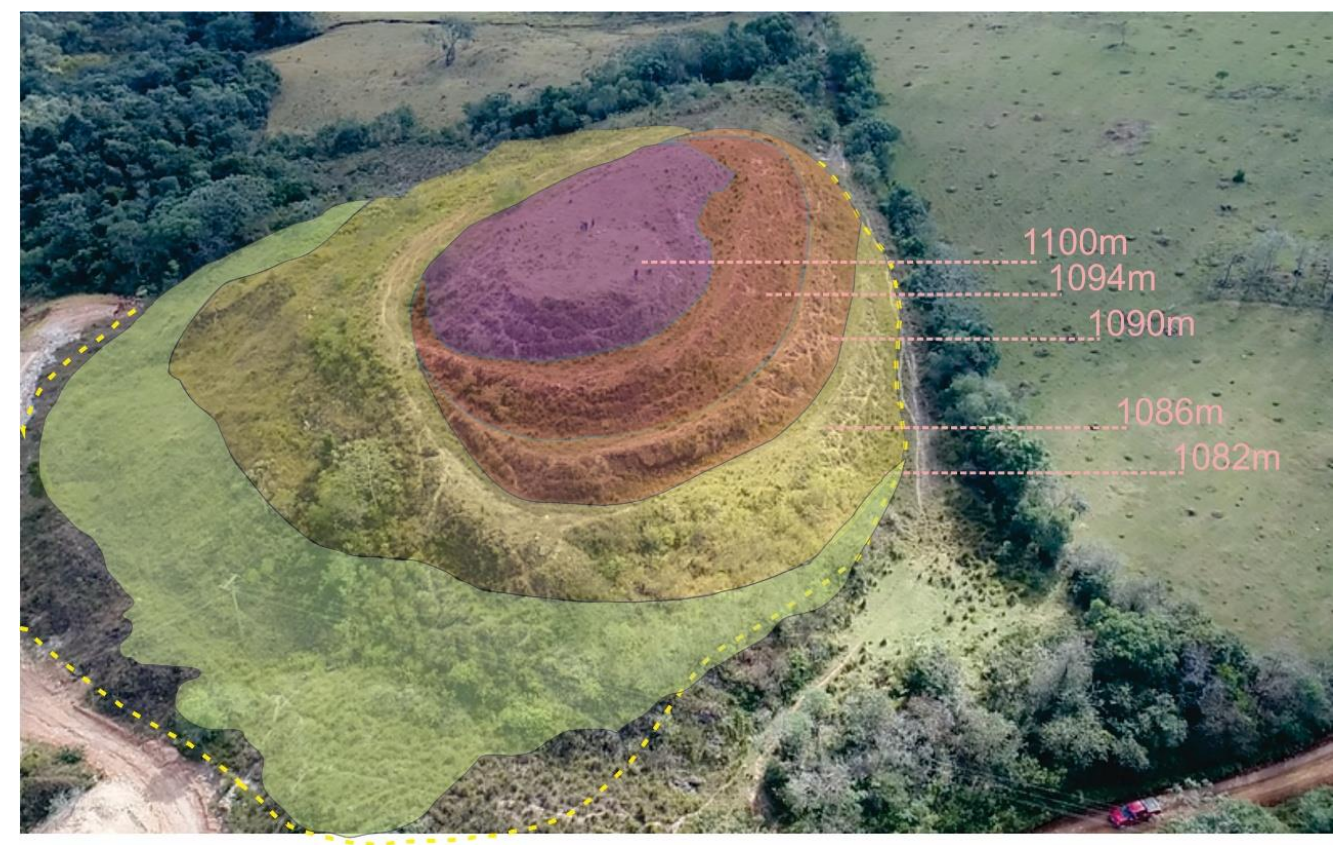

Figura 4 - Volumes movimentados pela atividade mineradora e impactos nas formas do relevo.

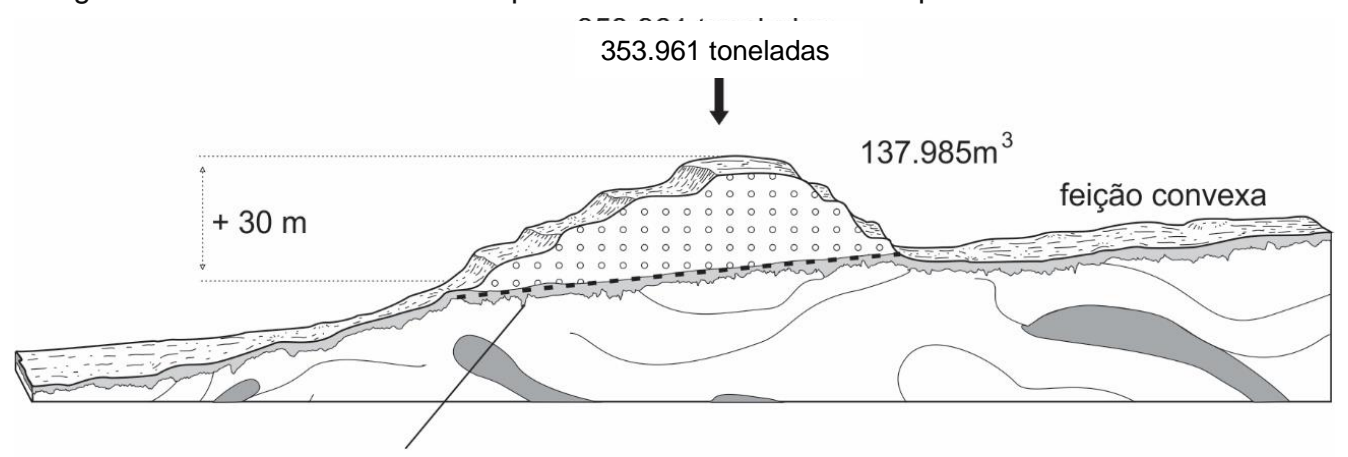

solo enterrado

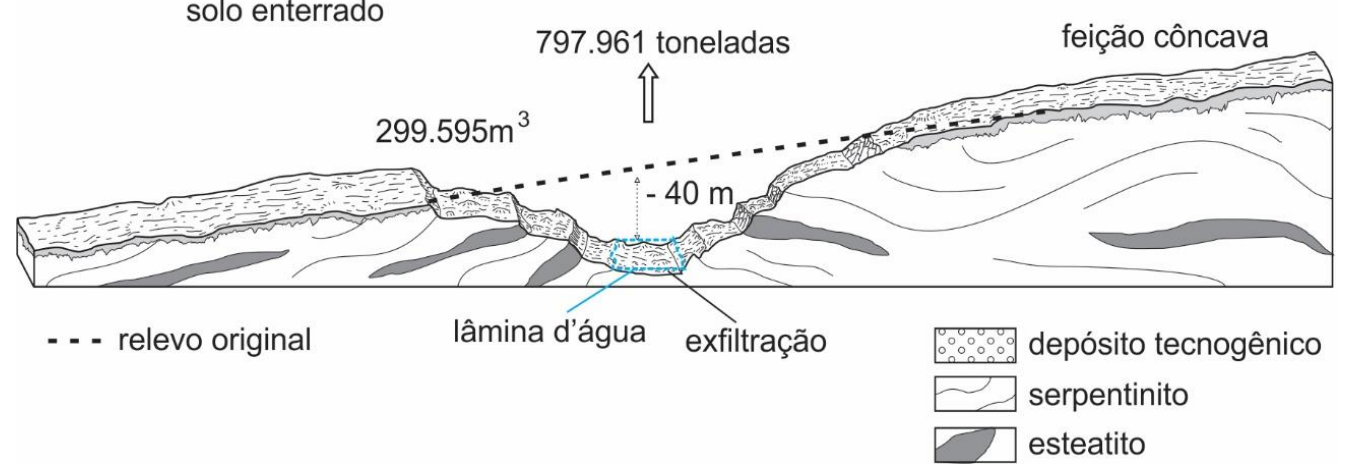


Ao considerar a densidade média do esteatito de $2750 \mathrm{~kg} \mathrm{~m}$-3 (DANA, 1978 apud ALMEIDA, 2006) e a do serpentinito de $2562 \mathrm{~kg} \mathrm{~m}-3$ (COLEMAN, 1971), conclui-se que cerca de 797.961 toneladas de material foram retiradas da área da cava, sendo depositados 353.286 toneladas enquanto pilha de rejeito. Como estimativa também se conclui que na área mineradora há cerca de $54 \%$ de esteatito e $46 \%$ de serpentinito, desprezando-se o volume do estéril por seu baixo valor significativo.

\section{DISCUSSÃO}

A gênese de um relevo antrópico perpassa necessariamente pela movimentação de materiais em volumes relativamente consideráveis na superfície terrestre e de maneira localizada. Tais movimentações podem ser representadas pela degradação, agradação ou mesmo transformação in situ destes materiais (PELOGGIA, 2019). Na exploração do esteatito no distrito de Santa Rita fica evidente a existência dos dois primeiros movimentos, com degradação de um relevo previamente esculpido, assim como a agradação a partir da acumulação por meio de uma pilha de rejeito.

O processo de denudação físico-químico e biológico, que rebaixaria essa paisagem em volumes consideravelmente expressivos, poderia levar milhões de anos, mesmo quando submetido a condições intempéricas intensas como as tropicais (CLEAVES, et al., 1974). A velocidade de tais mudanças é maior que a capacidade do meio em se adaptar e se reequilibrar, o que gera um input energético de transformações no sistema ambiental.

Neste trabalho é entendido que o denominado relevo antropogênico significa principalmente a somatória de evidências de interferências e distúrbios na fisiologia e fisiografia da paisagem diretamente associados às atividades humanas, que afetam principalmente os níveis de base que regulam os processos na superfície. A área de estudo evidenciou indicadores tanto morfológicos quanto hidrológicos que foram diretamente afetados pelo agente antrópico. A Figura 4 expressa a gênese de uma forte concavidade no terreno motivada pela mineração, capaz de alterar a dinâmica dos fluxos sedimentares e hidrológicos. A exposição das águas do lençol freático no fundo da cava também é um aditivo de vulnerabilidade das águas subterrâneas, visto que é uma área potencialmente contaminante pelo maquinário utilizado e os resíduos do pó das rochas exploradas.

Em contraponto, a principal pilha de rejeitos a norte da cava também representa uma forte interferência na paisagem. O modelado do relevo na área possui poucas variações abruptas de suas vertentes e colinas, sendo a pilha consolidada como uma proeminência morfológica capaz de potencializar a força do escoamento pluvial, além de movimentos gravitacionais motivados pela heterogeneidade dos tamanhos dos blocos das rochas que compõe a pilha. Essa feição acentuada na área representa um distúrbio no relativo equilíbrio que as formas do relevo adjacentes se formaram em condições naturais. Em termos de processos, esse relevo antropogênico acentua processos erosivos, motivados por uma paisagem que tenderá a equilibrar essa feição com as condições naturais vigentes para as demais áreas.

\section{CONSIDERAÇÕES FINAIS}

Os resultados deste trabalho evidenciaram que as investigações sobre relevo antropogênico são importantes, sobretudo, ao se considerar escalas relativamente locais e no tempo histórico humano. Alterações humanas promovidas na paisagem são capazes de interferir significativamente nos processos que regem a esculturação do modelado do relevo, tais como processos sedimentares de agradação e saída, bem como na dinâmica hidrológica tanto superficial quanto subsuperficial. As formas observadas na mineração de esteatito no distrito de Santa Rita se mostrou como um exemplo claro e didático de como esses distúrbios causados pelo agente antrópico afeta diretamente nos processos e materiais que formam a paisagem. 
Os dados levantamentos por meio de RPAS, tais como modelo digital de elevação, curvas de nível equidistantes de $1 \mathrm{~m}$, ortofotomosaico e cálculo de volumes de materiais, se mostraram em escala adequada para as investigações sobre os impactos humanos sobre a fisiologia e fisiografia da paisagem. Portanto, este trabalho também evidencia a importância do uso de bases em resolução espacial ideal para estudos em escala local, nos quais são ressaltados os processos atualmente vigentes como movimentos gravitacionais e fluxos hidrológicos. Sem uma escala adequada seriam ressaltadas somente as formas em detrimento da identificação de processos, o que compromete a análise sobre a gênese e evolução de relevos antropogênicos.

\section{AGRADECIMENTOS}

Os autores agradecem ao curso de Geografia do Instituto Federal de Minas Gerais - Campus Ouro Preto pelo empréstimo do RPAS.

\section{REFERÊNCIAS}

ALMEIDA, S. de. LAVRA, ARTESANATO E MERCADO DO ESTEATITO DE SANTA RITA DE OURO PRETO, MINAS GERAIS. 2006. Dissertação (Mestrado em Engenharia Mineral), Departamento de Engenharia de Minas, Universidade Federal de Ouro Preto, 2006

ALKMIM F.F., MARSHAK S. The Transamazonian orogeny in the Quadrilátero Ferrífero, Minas Gerais, Brazil: Paleoproterozoic collision and collapse in the Souhtern São Francisco Craton region. Precambrian Research, v.90, p.29-58, 1998. https://doi.org/10.1016/S0301-9268(98)00032-1

ANDRADE, C. F. Relevo antropogênico associado à mineração de ferro no quadrilátero ferrífero: uma análise espaço-temporal do Complexo Itabira (município de Itabira - MG). 2012, 129f. Tese (Doutorado). Pós-Graduação do Departamento de Geografia/Universidade Federal de Minas Gerais. Belo Horizonte, Minas Gerais, 2012.

ANDRADE, C.F.; VALADAO, R.C. Relevo Antropogênico: mineração de ferro e a interferência humana. 1. ed. Curitiba: Appris, 147p. 2016.

BALTAZAR,O.F.; BAARS,F.J.; LOBATO, L.M.; REIS,L.B.; ACHTSCHIN,A.B.; BERNI, G.V.; SILVEIRA,V.D. Mapa Geológico do Quadrilátero Ferrífero na Escala 1:50000 - nota explicativa. CODEMIG, Belo Horizonte, 2005.

BARROS, P. H. C. A.; VALADÃO. Aquisição e produção do conhecimento em geomorfologia: a investigação geomorfológica e seus conceitos fundantes. Geousp - Espaço e Tempo (Online), v. 22, n. 2, p. 416-436, 2018.

BLACHOWSKI,J.; MILCZAREK, W. Analysis of surface changes in the Walbrych hard coal mining grounds (SW Poland) between 1886 and 2006. Geological Quaterly, v.58, n.2, p.353-368, 2014. https://doi.org/10.7306/gq.1162

BROWN, E. H. O Homem modela a terra. Boletim Geográfico. Rio de Janeiro, v.30, n. 222, p. 3-18, 1971.

CLEAVES, E. T.; FISHER, D. W.; BRICKER, O. P. Chemical Weathering of Serpentinite in the Eastern Piedmont of Maryland. Geological Society of America Bulletin, v.85, n.3, p.437-444, 1974. https://doi.org/10.1130/0016-7606(1974)85<437:CWOSIT>2.0.CO;2

COLEMAN, R. G. Petrologic and Geophysical Nature of Serpentinites. Geological Society of America Bulletin, v.82,n.4, p.897-917, 1971. https://doi.org/10.1130/0016-7606(1971)82[897:PAGNOS]2.0.CO;2

CHRISTOFOLETTI, A. Modelagem de Sistemas Ambientais. Editora Edgard Blücher Ltda. 256p. 1999. 
DORR II, J.V.N. Physiographic, stratigraphic and structural development of the Quadrilátero

Ferrífero, Minas Gerais, Brazil. USGS/DNPM. Professional Paper 641-A. 110p. 1969.

https://doi.org/10.3133/pp641A

FELIPPE, M. F., JUNIOR, A. P. M., PESCIOTTI, H., COELI, L. Nascentes antropogênicas: processos tecnogênicos e hidrogeomorfológicos. Revista Brasileira de Geomorfologia, v.14, n.4, 2014. https://doi.org/10.20502/rbg.v14i4.210

FUJIMOTO N. S. V. M. Considerações sobre o ambiente urbano: um estudo com ênfase na geomorfologia urbana. Revista do Departamento de Geografia, São Paulo, v. 16, p. 76-80, 2005.

https://doi.org/10.7154/RDG.2005.0016.0008

GOUDIE, A. Human influence in geomorphology. Geomorphology, v.7, p. $37-59,1993$.

https://doi.org/10.1016/B978-0-444-89971-2.50007-9

HANCOCK, G.R.; LOWRY, J.B.C.; MOLIERE, D.R.; EVANS, K.G. An evaluation of an enhanced soil erosion and landscape evolution model: a case study assessment of the former Nabarlek uranium mine, Northern Territory, Australia. Earth Surf. Process. Landforms. v 33, p 2045-2063. 2008. https://doi.org/10.1002/esp.1653

HOOKE, R. L. On the History of Humans as Geomorphic Agents. Geology, v. 28, n. 9, p. 843-846, 2000. https://doi.org/10.1130/0091-7613(2000)028<0843:OTHOHA>2.3.CO;2

LANE, S.N.; CHANDLER, J.H. Editorial: the generation of high quality topographic data por hidrology and geomorphology: new data sources, new applications and new problems. Earth surface processes and landforms, v.28, n.3, p.229-230, 2003. https://doi.org/10.1002/esp.479

LUZ, C.C. da.; ANTUNES, A.F.B.; RATTON, P. Aplicabilidade da tecnologia VANT na atualização de base de dados cartográficos - Estudo de caso: sistema cárstico do rio João Rodrigues. Boletim paranaense de geociências, v.73, n.1, p.34-45, 2017. https://doi.org/10.5380/geo.v73i1.41428

OLIVEIRA, A.M.S.; BRANNSTRON, C.; NOLASCO, M. C.; PELOGGIA, A.U.G.; PEIXOTO, M.N.O.; COLTRINARI, L. Tecnógeno: registros da ação geológica do homem. In: C.R.G. Souza, K. Suguio, A.M.S. Oliveira, P.E. Oliveira (orgs.) Quaternário do Brasil. Ribeirão Preto, Holos, p. 363-378, 2005.

PELOGGIA, A.U.G. Conceitos fundamentais da análise de terrenos antropogênicos: o estudo da agência geológico-geomorfológica humana e seus registros. Revista do Instituto Geológico, v.40, n1, p.1-17, 2019. https://doi.org/10.33958/revig.v40i1.626

PRICE, S.; FORD, J.R.; COOPER, A.H.; NEAL, C. Humans as major geological and geomorphological agents in the Anthropocene: the significance of artificial ground in Great Britain. Philosophical transactions of the royal society, v.369, p.1056-1084, 2011. https://doi.org/10.1098/rsta.2010.0296

RODRIGUES, C. Morfologia Original e Morfologia Antropogênica na definição de unidades espaciais de planejamento urbano: um exemplo na metrópole paulista. Revista do Departamento de Geografia (USP), v. 17, p. 101-111, 2005. https://doi.org/10.7154/RDG.2005.0017.0008

SALGADO, A. A. R. Estudo da evolução do relevo do Quadrilátero Ferrífero, MG - Brasil, através da quantificação dos processos erosivos e denudacionais.2006, 125 f., Tese (doutorado em Evolução Crustal e Recursos Naturais), Departamento de Geologia, Universidade Federal de Ouro Preto, Université Paul Cezanne - AixMarseille III, 2006.

SOLARSKI, M. Anthropogenic transformations of the Bytom area relief in the period of $1883-1994$.

Environmental \& Socio-economic Studies, v.1, n.1, p.1-8, 2013. https://doi.org/10.1515/environ-2015$\underline{0001}$

SUMMERFIELD, M. A. Global geomorphology: Longman Scientific and Technical, Nova York: John Wiley and Sons Inc., 537 p., 1991. 
WÓJCIK, J. Mining changes on the example of the Walbrzych Basin relief (The Sudetes, Poland). Zietschrifts für Geomorphologie, v.52, n.2, p.187-205, 2013. https://doi.org/10.1127/0372$\underline{8854 / 2012 / 0090}$

Recebido em: 10/06/2020

Aceito para publicação em: 26/08/2020 